OPEN ACCESS

Edited by: Angel Borja,

AZTI, Spain

Reviewed by:

Joana Patrício

Executive Agency for Small and Medium-Sized Enterprises, Belgium

Jose Rafael Garcia March, Universidad Católica de Valencia San Vicente Màrtir, Spain

*Correspondence: Hector Andrade hector.andrade@akvaplan.niva.no

Specialty section: This article was submitted to Marine Ecosystem Ecology, a section of the journal Frontiers in Marine Science

Received: 02 June 2016 Accepted: 13 September 2016 Published: 04 October 2016

Citation:

Andrade H, Massabuau J-C Cochrane S, Ciret P, Tran D, Sow $M$ and Camus $L$ (2016) High Frequency Non-invasive (HFNI) Bio-Sensors As a Potential Tool for Marine Monitoring and Assessments.

Front. Mar. Sci. 3:187. doi: 10.3389/fmars.2016.00187

\section{High Frequency Non-invasive (HFNI) Bio-Sensors As a Potential Tool for Marine Monitoring and Assessments}

\author{
Hector Andrade ${ }^{1 *}$, Jean-Charles Massabuau ${ }^{2,3}$, Sabine Cochrane ${ }^{1,4}$, Pierre Ciret ${ }^{2,3}$, \\ Damien Tran ${ }^{2,3}$, Mohamedou Sow ${ }^{2,3}$ and Lionel Camus ${ }^{1}$ \\ ${ }^{1}$ Akvaplan-niva AS, Tromsø, Norway, ${ }^{2}$ Environnements et Paléoenvironnements Océaniques et Continentaux, UMR 5805, \\ University of Bordeaux, Arcachon, France, ${ }^{3}$ Centre National de la Recherche Scientifique, Environnements et \\ Paléoenvironnements Océaniques et Continentaux, UMR 5805, Arcachon, France, ${ }^{4}$ SALT Lofoten AS, Svolvær, Norway
}

Marine ecosystems all over the globe are facing multiple simultaneous stressors including rapid climatic change and increased resource exploitation, such as fishing, petroleum exploration and shipping. The EU-funded DEVOTES project (DEVelopment Of innovative Tools for understanding marine biodiversity and assessing good Environmental Status) aims to better understand the relationships between pressures from human activities and climatic influences and their effects on marine ecosystems. To achieve these goals, it is necessary among others, to test and validate innovative monitoring tools to improve our understanding of ecosystem and biodiversity changes. This paper outlines the application of a high frequency non-invasive (HFNI) valvometer as a potential tool for long-term marine monitoring and assessments. The principle of the method is based on the regular gaping behavior (closing and opening of the valves) of bivalve molluscs and the fact that physical or chemical stressors disrupt that gaping reference pattern. Bivalve gaping behavior is monitored in the natural environment, remotely, continuously over a time period of years, requirements that must be fulfilled if bivalve behavior is to be a useful biomonitoring tool. Here, we review the literature and highlight potential uses of the HFNI valvometry as a biosensor, to monitor and provide early-warning alerts of changes in water quality, such as global temperature increase, releases of contaminants and toxic algal blooms. Finally, potential relevant applications for monitoring and assessing environmental status of marine waters in the context of the Marine Strategy Framework Directive are identified. Relevant descriptors, criteria, and indicators of Good Environmental Status that might be monitored using the HFNI valvometer are discussed for monitoring bathing beaches and harbors, petroleum installations and aquaculture sites.

Keywords: chronobiology, environmental monitoring, valvometry, rhythmicity, real time data

\section{INTRODUCTION}

Marine ecosystems all over the globe are facing multiple simultaneous stressors including rapid climatic change and increased resource exploitation, such as overfishing, petroleum exploration and shipping. To protect more effectively the marine environment across Europe, Member States of the European Union committed to adopting an ecosystem approach to marine management. 
The EU Marine Strategy Framework Directive (MSFD 2008) mandated Member States to assess the environmental status of their territorial waters by July 2014, and to develop strategies to achieve "good environmental status" within 2020 (European Commission, 2008). The DEVOTES project (DEVelopment Of innovative Tools for understanding marine biodiversity and assessing good Environmental Status) aims to better understand the relationships between pressures from human activities and climatic influences and their effects on marine ecosystems, including biological diversity, in order to support the ecosystem based management and fully achieve the Good Environmental Status (GES) of marine waters. Among the main objectives is to develop, test and validate innovative integrative modeling and monitoring tools to improve our understanding of ecosystem and biodiversity changes (www.devotes-project.eu/).

This paper outlines the application of high frequency non-invasive (HFNI) valvometers (http://molluscan-eye.epoc. $\mathrm{u}$-bordeaux1.fr/index.php?lang $=$ en\&page $=$ enregis\&wid $)^{1}$, as a potential tool for marine monitoring and assessments. The aim of this article is to provide a brief description of how the HFNI valvometer works, review some results achieved so far by studying bivalve gaping behavior with this method under both natural and laboratory conditions and discuss how the HFNI can be employed in the context of the Marine Strategy Framework Directive as a biosensor. A literature review is carried out to provide an overview of the geographic locations where the technology has been deployed, the species tested and the effect of different environmental and anthropogenic drivers and stressors upon valve behavior, growth and reproduction.

\section{THE HFNI VALVOMETER AND THE PRINCIPLES OF THE METHOD}

The HFNI valvometer is a high frequency (10 Hertz), noninvasive (HFNI) biosensor employed to monitor gaping behavior (closing and opening of the valves) of bivalve molluscs. It is a new-generation remote technique enabling the online study of the behavior of bivalve molluscs living in their natural habitat, without interfering with normal behavior. Gaping activity of many species is closely related to physiological processes such as breathing and nutrition and waste elimination which respond to environmental conditions following rhythmic cycles (GarcíaMarch et al., 2008; Sow et al., 2011; Tran et al., 2011). Bivalves alter their normal gaping behavior in the presence of stressors, indicating perturbations in the environment (e.g., Tran et al., 2003; Fournier et al., 2004; Sow et al., 2011) and this can be employed for marine monitoring and assessments. In a typical HFNI field deployment, a pair of electrodes with 1-1.5 m flexible cables are glued on to each half shell of 16 bivalves (Figure 1). The electrodes, designed to minimize disturbance to bivalve's behavior, are made up of two resin-coated electromagnets $(56 \mathrm{mg}$ each). An electromagnetic current between the electrodes is generated allowing measurement of the amount of valve opening

${ }^{1}$ MolluSCAN eye, the website. http://molluscan-eye.epoc.u-bordeaux1.fr/index.php ?rubrique $=$ accueil\&lang $=$ en $\&$ site $=$ EYRAC. and closing (Sow et al., 2011). At minimal distance, the electronic noise contribution to the signal is minimal ( $\leq 1 \mu \mathrm{m})$.

In a classic HFNI valvometer deployment, each pair of electrodes is coupled to a waterproof box next to the animals. This box contains a first stage analogical electronic card that manages the electrodes. The first stage card is connected to a second held on the sea surface, or located on land by an umbilical cable. The whole system constitutes a Linux embedded system that acquires, saves and digitizes the data for transfer to the laboratory workstation (Figure 2). The system is built to sample data at $10 \mathrm{~Hz}$ from 16 animals in a sequential order. Every $0.1 \mathrm{~s}$, three packets of information are produced: distance between valves at the electrode level, sampling time, and animal number. Thus, as a whole, a total of $3 \times 864,000$ pieces of information/day describes the behavior of a whole group of 16 animals $(2,592,000$ data points/day). At the individual level, it means that today the system performs a measurement of the opening status every $1.6 \mathrm{~s}$, and that a total of 54,000 data points characterizes the gaping/closing behavior of any individual every day. If more than 16 animals are needed in a deployment, up to four systems can be installed. The raw data is transferred from the field to the laboratory using either an Ethernet network socket or a cellular telephone network (GPRS; General Packet Radio Service), with a mobile phone module embedded in the second electronic card. In both cases, data are transferred daily at 00:00 GMT local time (a standard configuration that can be modified) to a laboratory workstation where analyses are performed using both Bash Linux and mathematical codes written in $\mathrm{R}$, (https://cran.r-project.org/). Thus, basically, the system architecture is composed of multiple robust slave-modules in the field (low to very low energy consumption, $0.5-1$ watt; high-precision) and a single powerful master workstation in Arcachon, France, to handle megabytes of daily data. The latter is designed to capture, process and distribute information derived from the original data on the web (Sow et al., 2011).

The data generated are processed and analyzed on a daily basis, and easy-to-read graphs are automatically produced. In this manner daily, weekly or monthly trends can be identified quickly, offering a real-time monitoring framework to investigate the environmental status of multiple marine ecosystems. The metadata also is stored, providing a background allowing for gaping behavior comparisons when any change, subtle, overt or violent occurs over time. Records for all the sites where the HFNI has been deployed remain available since their original launch (the first one was done in February 2006), thanks to a data stocking policy and two back-ups located in two geographically different sites. Registered users have access to all the records from the individuals deployed at their site using the PRO website version. Here dynamic graphs deploy simultaneously gaping behavior of 1,4 , or 16 bivalves. The PRO version also allows inter-site comparisons.

In the pages of MolluSCAN eye PRO, professionals can integrate various types of information and derive graphs describing the various aspect of the bivalve's ethology, chronobiology or physiology. The graphs allow the relevance of single observations to be placed in a broader context 

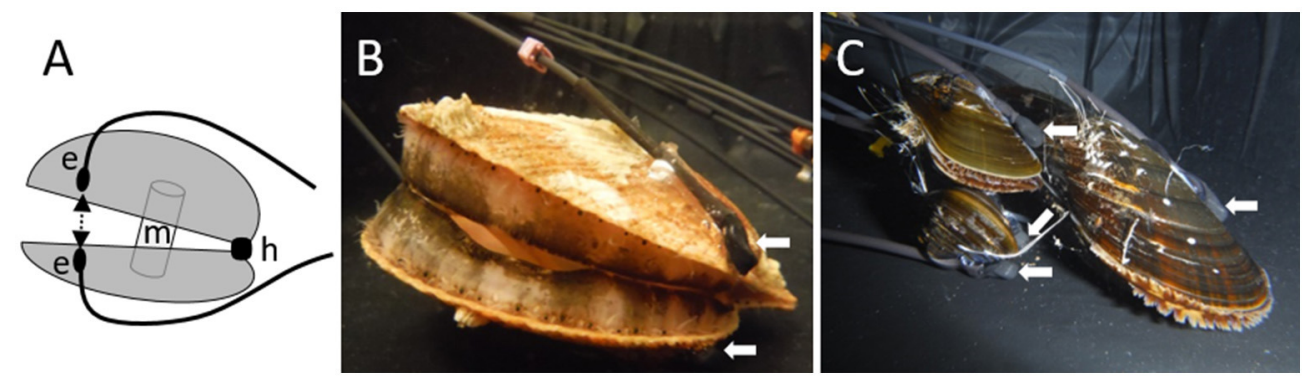

FIGURE 1 | Schematic representation of the High frequency non-invasive electrodes glued to a bivalve (A) showing the position of the electrodes (e), the muscle ( $\mathbf{m}$ ) and the hinge (h). The Icelandic scallop Chlamys islandica (B) and blue mussels Mytilus edulis (C) are some of the latest species where the HFNI valvomenter is employed. The white arrows indicate the position of the electrodes. Photo credit: J-C Massabuau.

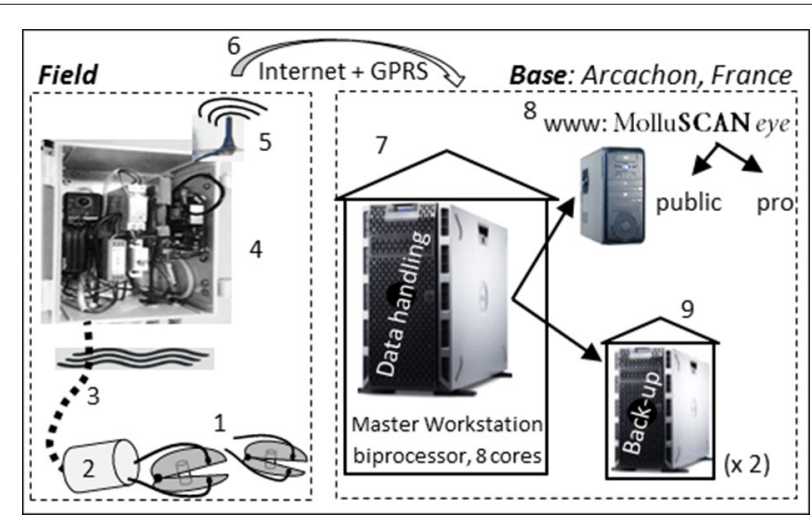

FIGURE 2 | Synoptic representation of a MolluSCAN eye system, from field to laboratory. (1) Clams equipped with a couple of electrodes, (2) 1st level electronic card in a waterproof box close to the clams; (3) electrical connection between the first and the second electronic cards (umbilical); (4) 2nd level electronic card out of water; (5) GPRS antennae (6) GPRS and Internet connection; (7) Marine Station of Arcachon (Master unit) ready for daily update and for feeding internet (Google: molluscan eye); (8) daily update on internet for the general public (restricted access) and professionals (full access), (9) two back-up located in two geographically distinct places. Basically, the system architecture is composed of robust slave-modules in the field (1-5; energy consumption, 1 watt) and a single powerful master workstation (7) in Arcachon, France, to handle megabytes of daily data.

of comprehensive behavior, especially when the system is coupled with a multi-parameter probe. Five key examples of the types of data produced are shown on the website (http://molluscan-eye.epoc.u-bordeaux1.fr/index.php?rubrique= contenu_sitePro\&lang=en): biological rhythms, growth rates, spawning and death records and disturbance by toxic algae.

To model bivalve behavior, a non-parametric modeling approach based on kernel estimations is employed. This method has the advantage of summarizing complex data into a simple density profile obtained from each animal at every 24-h period, to ultimately make inference about time effect and external conditions on this profile (Sow et al., 2011; Tran et al., 2011). Hypotheses can be formulated to study bivalve biological rhythms and how local environmental drivers affect valve activity, e.g., tide amplitude, light regime, temperature, chlorophyll $a$, turbidity, etc. (Schwartzmann et al., 2011; Sow et al., 2011; Mat et al., 2012, 2013; Tran et al., 2016). The rationale behind the principle is that reference behavior and biological rhythms are basically synchronized by an endogenous molecular clock and external environmental factors (Tran et al., 2011).

The effects of external stressors such as pollution and climate change upon bivalve activity can be studied by comparing experimentally (under laboratory and/or field conditions) whether deviations from normal expected gaping patterns occur. The main goal in such experiments has been to test whether the HFNI valvometer can be effectively employed as a viable biosensor for water-quality assessment. Comparisons are made by either contrasting valvometry records prior to and after the introduction of a stressor, or by carrying out exposure experiments between treatment (exposed) and control (unexposed) units. Behavioral parameters such as valve opening duration, valve amplitudes, etc. are recorded and compared (Figure 3). In the case of bivalve exposures to toxic substances for example, a minimal sensitivity threshold can be calculated as the trace element concentration inducing a valve closure on 50\% of the exposed organisms. By recording the time when alterations occur, it is possible to derive dose-response curves as well as timeresponse curves (Tran et al., 2003, 2004, 2007; Fournier et al., 2004).

Growth rates have been measured using the HFNI valvometer based on the fact that calcification in bivalves occurs in the mantle cavity, all over the shell's internal structure (Figure 4). When daily growth layers are deposited, the minimum distance between the electrodes glued to the shells increases providing a good proxy of growth (Schwartzmann et al., 2011; Berge et al., 2015). In the same manner, the maximum daily valve opening can be used to trace the overall health condition of the bivalves. Maximal opening status in bivalves is an index of a clam's well-being, because decreasing the valve opening is employed by bivalves as a primary strategy to protect the soft tissues when under threat (Schwartzmann et al., 2011). By plotting these values of minimal and maximum daily valve opening, mortality events can be easily distinguished as when a bivalve dies, its valves become widely open and inert. Comparisons to typical records allow to establish the exact time, up to the minute, at which the adductor muscle ceases to contract. 


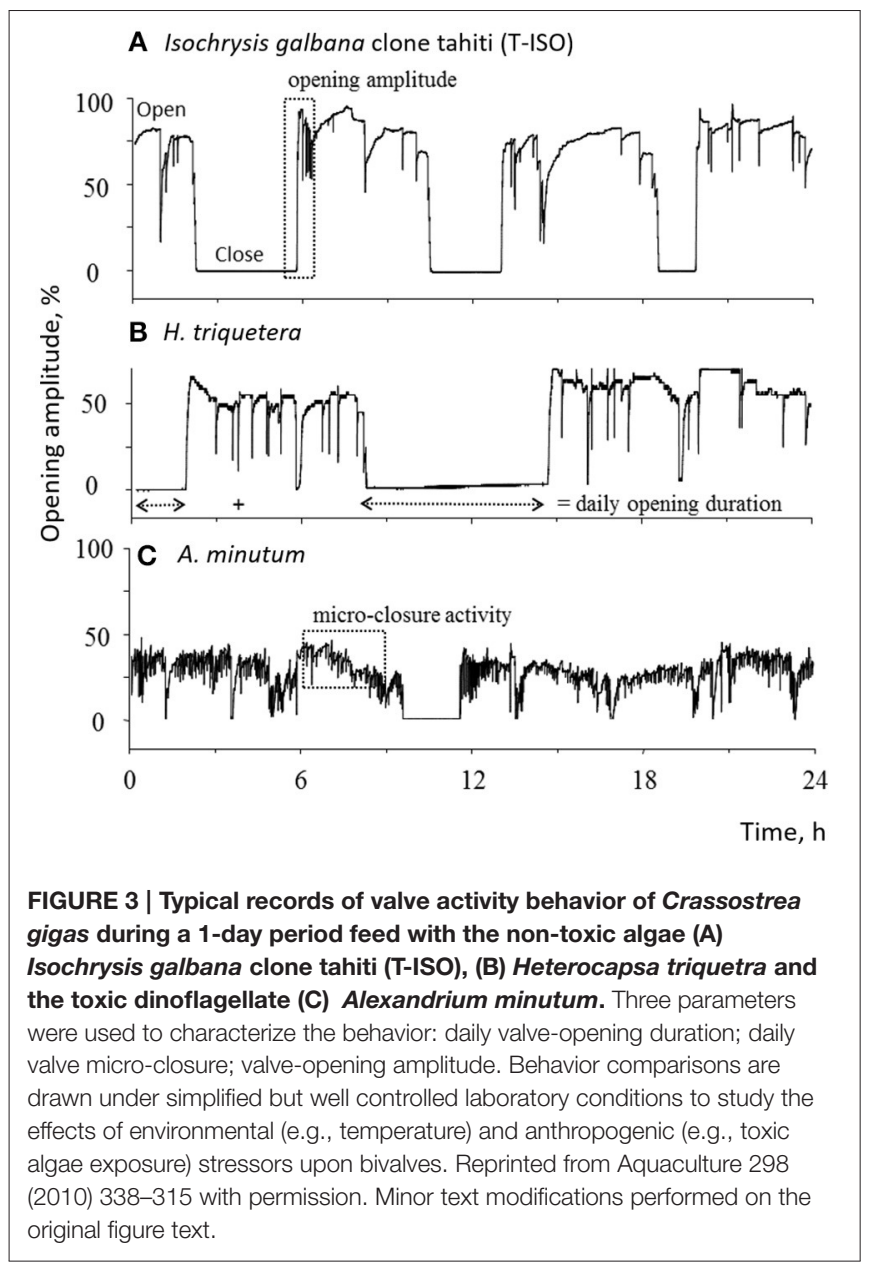

\section{CASE STUDIES OF APPLICATION OF HFNI}

Gaping behavior in bivalves has been studied using the HFNI valvometer both in the field and under laboratory conditions. Gaping behavior in the field has been recorded from tropical to arctic locations, for up to nearly four years continuously without human intervention (Table 1). At these locations, the biological rhythms of several native species have been studied as well as how extreme environmental conditions (e.g., increased water temperature, storms) affect their gaping behavior. Growth and reproduction events have also been recorded remotely, over multiple-year cycles allowing to study life history aspects of bivalves. Investigations have been conducted to assess the effects of toxins upon the behavior of several species using the HFNI valvometer in the laboratory. Ecotoxicology experiments are allowing to develop the HFNI technology as a biosensor for anthropogenic impacts in marine and freshwater.

\section{Valve Behavior, Growth and Reproduction of Bivalves}

Patterns of valve behavior, growth rates and/or reproduction activity have been studied thoroughly in the giant clam Hippopus

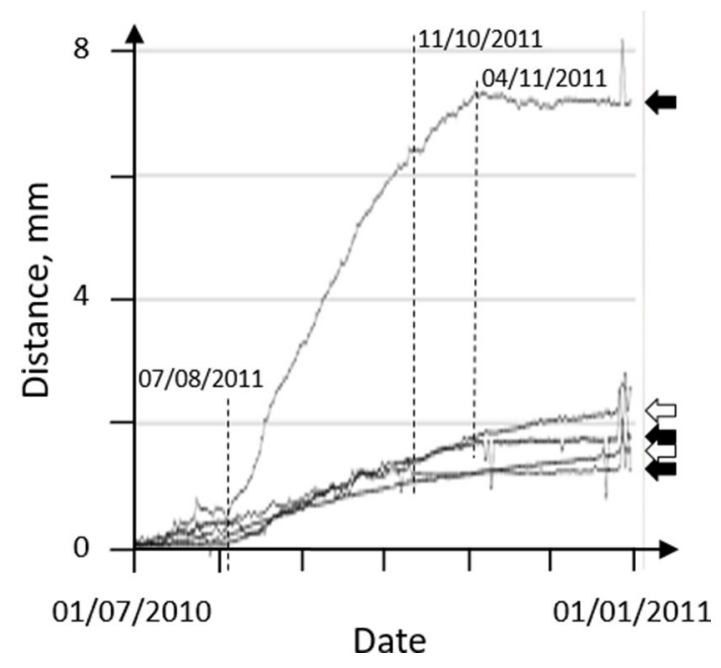

FIGURE 4 | Growth index in 5 Pacific oysters Crassostrea gigas recorded by HFNI valvometry from 1 July 2010 to 31 December 2011 in the Bay of Arcachon, France. The index corresponds to the minimum daily opening value measured between HFNI electrodes as shown in Figure 1. White arrows, 2 oysters with continuous growth; black arrows, 3 oysters exhibiting a growth arrest which started during the period 11 October -4 November 2011 (dashed lines), at the beginning of the winter period. Note the growth rate acceleration that started in early August.

hippopus, the Pacific oyster Crassostrea gigas (Figure 3) and the Icelandic scallop Chlamys islandica at their natural locations.

In New Caledonia, it has been shown that patterns of daily behavior and growth rate of the giant clam were related to light availability and changes in water temperature (Schwartzmann et al., 2011). Growth rate, as measured by HFNI valvometry, was demonstrated to be continuous throughout the year, but periods of both zero and altered daily growth were recorded. Typically, giant clam valves were open during the day and partially closed during the evening. This pattern became erratic during stressful environmental conditions brought about by a cyclone, and during increased irradiance periods and maximum temperatures $\left(>27^{\circ} \mathrm{C}\right)$ in the summer months. The later indicated that the species might be living beyond its upper thermal comfort limits during the summer at this location (Schwartzmann et al., 2011).

Growth patterns and daily behavior also have been studied in the Icelandic scallop C. islandica using HFNI valvometry. Above the polar circle (at $79^{\circ} \mathrm{North}, \mathrm{Ny}$-Ålesund) it was shown that despite what one might expect, growth rates of this bivalve can be similar during the polar night compared to the rest of the year (Berge et al., 2015). Behavior records showed that the valves of scallops remained opened most of the time and showed a steady biological rhythm suggesting that metabolism is kept active without any marked resting periods. The results showed that despite the seasonal polar night/day cycles, Icelandic scallops maintain a circadian rhythm for the majority of the year much like bivalves at other latitudes (Mat et al., 2012; Tran et al., 2016).

Reproduction and spawning behavior have been studied for the Pacific oysters Crassostrea gigas in the Bay of Arcachon and the Bay of Marennes-Oléron, France using the HFNI valvometer 
TABLE 1 | Field deployments of the HFNI valvometer (without in situ human intervention) as reported in peer-reviewed literature.

\begin{tabular}{|c|c|c|c|c|}
\hline Location & Species & Deployment duration & Aspect studied & References \\
\hline \multirow{3}{*}{$\begin{array}{l}\text { Bay of Arcachon and } \\
\text { Marennes-Oléron, French } \\
\text { Atlantic Coast }\end{array}$} & \multirow{3}{*}{$\begin{array}{l}\text { Pacific oyster Crassostrea } \\
\text { gigas }\end{array}$} & 6 months & Growth, biological rhythms & Sow et al., 2011 \\
\hline & & 12 months & Biological rhythms & Tran et al., 2011 \\
\hline & & $1-11$ months & $\begin{array}{l}\text { Spawning behavior, timing, } \\
\text { environmental triggers }\end{array}$ & Bernard et al., 2016 \\
\hline $\begin{array}{l}\text { Southern lagoon of New } \\
\text { Caledonia }\end{array}$ & $\begin{array}{l}\text { Giant clam Hippopus } \\
\text { hippopus }\end{array}$ & 12 months & $\begin{array}{l}\text { Growth, biological rhythms, effects of } \\
\text { environmental stress }\end{array}$ & Schwartzmann et al., 2011 \\
\hline $\begin{array}{l}\text { Ny-Ålesund, Svalbard } \\
\text { Archipelago }\end{array}$ & $\begin{array}{l}\text { Icelandic scallop Chlamys } \\
\text { islandica }\end{array}$ & $\begin{array}{l}36 \text { months } \\
44 \text { months }\end{array}$ & $\begin{array}{l}\text { Growth during polar night Biological } \\
\text { rhythms }\end{array}$ & Berge et al., 2015; Tran et al., 2016 \\
\hline
\end{tabular}

(Bernard et al., 2016). Spawning behavior in female Pacific oysters is characterized by rapid contractions of the adductor muscle. This gaping signal is recorded by the HFNI valvometry as several rapid and ample movements (large openings) of the valves and allows for studying in detail the exact timing and possible environmental drivers of spawning activity. Spawning events between 2003 and 2014 consistently occurred during spring high tides at both locations, when the moon is closest to the earth (perigee). Peaks in water current were proposed as the final spawning trigger (Bernard et al., 2016). On the whole, the above studies demonstrate that the HFNI valvometer has been successful to investigate various aspects of bivalve life history and how these are affected by the prevailing environmental drivers.

\section{Trace Metal Detection}

Initial try-outs with the HFNI system were carried out on the freshwater mussel Corbicula fluminea to test the potential and limitations of using bivalves as a rapid response and/or sensitive biosensor for different contaminants (Tran et al., 2003). Under laboratory conditions, C. fluminea was exposed to increased levels of cadmium, copper, uranium and inorganic mercury in independent experiments to test whether gaping behavior differed between exposed and unexposed organisms. The experiments effectively showed that changes of valve closure patterns occurred in organisms exposed to increasing trace metal concentrations. Importantly, time was taken in consideration and an inverse relationship between concentration and response velocity was systematically demonstrated in all conditions. Minimal sensitivity threshold, i.e., the trace element concentration inducing a valve closure on $50 \%$ of the exposed organisms were calculated as well as the time needed to achieve such closures (Tran et al., 2003, 2004, 2007; Fournier et al., 2004). Cadmium concentrations above $50 \mu \mathrm{g} / \mathrm{l}$ could be detected within less than $1 \mathrm{~h}$. The lowest cadmium concentration detected was $16 \mu \mathrm{g} / \mathrm{l}$ and required $5 \mathrm{~h}$ of exposure (Tran et al., 2003). Copper concentrations as low as $4 \mu \mathrm{g} / \mathrm{l}$ were detected within $5 \mathrm{~h}$ (Tran et al., 2004). For uranium, the minimal sensitivity threshold varied depending on the $\mathrm{pH}$. At $\mathrm{pH} 5.5$, minimum detection levels at $0.05 \mu \mathrm{mol} / \mathrm{l}$ were achieved after $5 \mathrm{~h}$ (Fournier et al., 2004). In a latter experiment using inorganic mercury, minimum detection occurred at $3 \mu \mathrm{g} / \mathrm{l}$ at the same exposure time (Tran et al., 2007). Interestingly, the inorganic mercury experiment showed that stressed valve behavior of C. fluminea exposed was different from those exposed to the other trace metals indicating that pollutants might produce a contaminantspecific gaping signal. In general, these studies demonstrated that the HFNI valvometer has potential as a biosensor for monitoring anthropogenically induced trace metals in the water column.

\section{Algal Toxicity}

Bivalves are filter-feeders that can accumulate paralytic shellfish toxins which are harmful to human health (Bricelj and Shumway, 1998). Experiments using the HFNI valvometry tested whether increased concentrations of these toxins could modify the valve behavior of Pacific Oysters C. gigas (Figure 3). Under laboratory conditions, oysters were exposed to various simulated algal blooms of the toxic dinoflagellate Alexandrium minutum and the non-toxic dinoflagellate Heterocapsa triquetra or the Isochrysis galbana clone Tahiti. Gaping behavior of oysters differed between toxic and non-toxic treatments and were detected after $\approx 1 \mathrm{~h}$. Organisms exposed to A. minutum increased both micro-closure activity and daily valve-opening duration while valve-opening amplitude decreased (Tran et al., 2010; Haberkorn et al., 2011; Mat et al., 2013). In a later study it was shown that daily gaping rhythmicity completely vanished in oysters exposed to the harmful algae (Tran et al., 2015). These results demonstrate that the HFNI vavometer have the potential to be employed to monitor toxic algal blooms.

In general, the heavy metal and algae toxicity experiments have shown that the HFNI technology has been effective to detect toxic substances in the water under laboratory conditions. The methodological changes developed with the HFNI valvometer allowed to better define the optimal response capacities of various bivalves in simplified, although perfectly controlled, conditions. In this regard, the HFNI technology has a clear potential as a biosensor to monitor water quality.

\section{HFNI-AN INNOVATIVE TECHNOLOGY}

As demonstrated by the papers reviewed here, the HFNI valvometry has been employed successfully to study multiple life history traits (biological rhythms, growth rate, spawning events, death) of several bivalve species in relation to their natural environment and in ecotoxicological studies as a biosensor for 
various toxic substances and contaminants. The use of various technical designs to record molluscan gaping behavior, for the purposes of water quality assessment is not new in principle (see for example http://www.mosselmonitor.nl/, although other systems also exist; Kramer et al., 1989; Borcherding, 2006; Kramer, 2009; Chen et al., 2010). However, the HFNI valvometer differs from others in a number of significant ways:

- The sensors are lightweight, causing minimal or no disturbance to the animals. It has been shown that valve behavior does not differ between equipped and unequipped bivalves (e.g., Tran et al., 2003);

- The animals are kept in as close to their natural habitat as possible-in hanging cages and/or in suitable substrates allowing experiments to be performed in situ;

- Once installed, the sensors are long-term maintenance-free as demonstrated by the 3-year and 9-months record presented by Tran et al. (2016) in arctic conditions. To our knowledge, no other system has operated consistently for several years even in the laboratory;

- Clams continuously clean themselves, and the system is designed to utilize this function, resulting in a built-in antifouling function;

- The data are delivered cable-free, automatically streamed to a mobile phone line or an internet socket, and uploaded onto a website (search on the Internet "molluscan eye" or http://molluscan-eye.epoc.u-bordeaux1.fr/index.php?rubrique 5accueil\&lang5en), and automatically treated, in near real-time, where easily read graphs can be viewed continuously;

- The system works with both marine and freshwater bivalve species. To date tests have been carried out with blue and brown mussels Mytilus edulis and Perna perna, giant tropical clams Hippopus hippopus and Tridacna maxima, Icelandic scallops Chlamys islandica, black scallops (Chlamys varia), grooved carpet shell (Ruditapes decussatus), Pacific oysters Crassostrea gigas, black-lip pearl oysters (Pinctada margaritifera) and Asiatic clams Corbicula fluminea;

- The system today is the only one to our knowledge which allows for simultaneous recordings of clam growth (Schwartzmann et al., 2011), valve activity behavior (Tran et al., 2010), biological rhythms (Tran et al., 2011) and spawning (Bernard et al., 2016);

- The developed software and algorithm allows the simultaneous near real-time treatment of the data produced by up to 16 animals per system, daily to quickly identify the key biological life history traits of the animal and the environmental drivers (Sow et al., 2011);

- The system allows to identify very precisely, i.e., up to the minute or less, when animals die. This results from the relaxation of the abductor mussel which leaves the valves open in a very specific way;

- The system allows to identify very clearly when the animal is spawning, up to the minute or less, and to potentially predict the spawning time with accuracy (Bernard et al., 2016). This is a strong sign of clam welfare and good water quality. Beyond its power to characterize healthy clam populations and ecosystems, this attribute may have an application in commercial mussel farm areas.

\section{HFNI AS A POTENTIAL TOOL FOR MSFD MONITORING}

\section{General Applications}

The current set-up of the non-invasive sensor system is applicable to the monitoring phase of the MSFD (Marine Strategy Framework Directive), assess the environmental status across the European seas. Within the MSFD, Good Environmental Status (GES) is defined in terms of 11 qualitative descriptors, within which a total of 29 associated criteria and 56 indicators have been identified, which include biological, physico-chemical state indicators as well as pressure indicators (EU Commission Decision of 1 September 2010 on criteria and methodological standards on good environmental status on marine waters (European Commission, 2010). In short, the descriptors as listed by Borja et al. (2013) comprise Biological diversity (D1), Non-indigenous species (D2), Exploited fish and shellfish (D3), Food webs (D4), Human-induced eutrophication (D5), Seafloor integrity (D6), Hydrographic conditions (D7), Contaminants (D8), Fish and seafood contaminants (D9), Marine litter (D10) and Energy including underwater noise (D11). The HFNI can be directly employed to monitor the descriptors Human-induced eutrophication (D5), Contaminants (D8, D9) and Noise (D10), but also indirectly Sea-floor integrity (D6) and Food webs (D4). However, the method is most suitable for long-term, 24/7, insitu monitoring of changes in water quality-not in terms of actual values measuring directly an indicator (e.g., nutrient concentration in the water column), but in terms of arising disturbances, either acute or gradual (e.g., abnormal gapping behavior due to increased concentration of nutrients in water). If the continuous data feeds do not show any abnormalities, then one may assume the water quality is as usual (according to previously measured levels). If there is a change, either abrupt or progressive (in case of silent pollution), then it will provide an early-warning that a change has occurred, and a more detailed water quality measurement can be done, should this be the appropriate action. An alarm system would make monitoring of the deployed systems efficient in terms of human effort.

Three important points have to be considered when using HFNI valvometry for detection of toxic substances in the water: first, the valve behavior due to stress of the experimental set-up must be minimized; second, the natural valve closing/opening rhythm (equivalent to background noise) has to be defined so that optimal comparisons can be made between stressed and unstressed organisms; and third, mathematical descriptions using analysis of the dose-response-type curves that integrates time of any detection mechanism(s) must be developed (e.g., Tran et al., 2003). Some relevant monitoring applications are described below (in alphabetical order):

\section{Aquaculture Sites}

At aquaculture sites, where it is not possible to locate the cage groups in exposed or deep water, a form of online 
monitoring alerting to changes in water quality can contribute to maintaining efficient fish health and thus growth. Especially in areas where seasonal upwelling is prominent, an early-warning of deterioration in water quality, usually as a result of over-enriched sea-floor conditions, could in the most extreme case prevent mass mortalities due to oxygen depletion. If the clam sensors indicate stressful conditions, then quantitative water measurements can immediately be carried out. Direct and indirect effects of nutrient enrichment, increased contaminant concentrations and organic matter over a threshold level can be detected as abnormal behavior in bivalves prompting an immediate monitoring response where more exhaustive sampling is required. Such sampling would include among others, nutrient and contaminant concentrations in the water column, turbidity and oxygen levels. Temporary transfer of cages to a less exposed area could be a remedial action from such a warning.

Additionally, as mentioned above, the sensors allow the detection and possibly also prediction of spawning behavior, which may have considerable application to bivalve farms (using the same species been farmed as a biosensor). The collection of larvae at the appropriate timing is of considerable value in bivalve farming, thus knowledge of when animals are spawning is a key piece of information. Another application might be to infer upon causes of decreases in bivalve growth, as shown for oysters infected with parasites (Chambon et al., 2007).

From a management perspective, the main potential environmental impacts of aquaculture come from the introduction of non-indigenous species, nutrients, organic matter, contaminants including pesticides and litter, the disturbance to wildlife, and the possibility for escape of farmed fish (European Commission, 2016). The based on the papers reviewed here, the HFNI valvometer could potentially detect evidence of increased eutrophication in enclosed areas (D5), declining sea-floor integrity due to siltation (D6) and the presence of contaminants in the form of hazardous substances and microbial pathogens (D8).

\section{Bathing Beaches and Harbors}

EU Member States monitor the quality of their bathing sites according to the provisions of the EU's revised Bathing Water Directive (2006/7/EC). This directive requires Members States to monitor and assess the bathing water for at least two parameters of (fecal) bacteria and prepare bathing water profiles containing information about the kind of pollution and sources that affect the quality of the bathing water (http://ec.europa.eu/ environment/water/water-bathing/index_en.html). Recordings of molluscan gaping behavior at bathing beaches or harbors will allow detection of change in water quality assisting in monitoring the MSFD descriptors Human-induced eutrophication (D5) and Contaminants (D8) (European Commission, 2010). A working hypothesis would be that if the clams behave as normal, we may assume no adverse change has occurred. If a sudden change is episodic, it could be linked with a single event, but if the aberrant behavior persists, then quantitative monitoring of water quality should be implemented. Coupled with the actual measurements of toxic algal blooms, bacterial content and other contaminants, this would provide an efficient system to safeguard human safety, even during periods where daily physical measurements are not being carried out by the municipality (see Sections Contaminant Detection and Toxic Algae Alerts). The system would have a further public appeal, because the information would be made available in a user-friendly way on an openly accessible web site. Television reporters have covered a story about these ideas on the Franco-German TV station, ARTE in 2009 (X:enius, 15/7/2009), which illustrates the public interest for such questions (Oberhauser, 2009).

\section{Climate-Related or Other Changes in Hydrographic Properties}

The HFNI valvometer allows the user to relate changes in bivalve behavior and growth rate to climate-induced stress. As mentioned above, the valve activity and growth of the giant clam $H$. hippopus becomes erratic at increased temperatures and solar irradiance (Schwartzmann et al., 2011). Moreover, bivalve populations at the edge of their thermal maxima (temperature above which most individuals respond with unorganized locomotion, subjecting the animal to likely death) can present massive mortalities due to effects of increased temperature (Jónasson et al., 2004) and can be recorded and dated with the HFNI system as dead bivalves remain with the shells open and motionless. To investigate further valve activity behavior and life history of bivalves near their thermal limits, 16 individuals of the blue mussel M. edulis have been deployed in the high Arctic archipelago of Svalbard in April 2016. Blue mussels were absent from this location for about 1000 years but new settlements have recently re-colonized the area due to increased sea surface temperatures along the west coast of Svalbard (Berge et al., 2005). In general, these investigations show the HFNI technology potential to study effects of climate variability upon bivalves in tropical and arctic environments.

Relationships between primary productivity and bivalve growth established with the HFNI can also provide information relevant to the Descriptor 4 "Food Webs" (European Commission, 2010). Filter-feeding bivalves use their gills to catch particulate food such as phytoplankton. The latest HFNI deployments include a multi-parameter probe equipped with a fluorometer that estimates chlorophyll production, a widely used index of phytoplankton biomass. Effects of increased phytoplankton biomass on bivalve growth rates can then be easily studied with this approach, providing an indicator of trophic level productivity and trophic interactions.

\section{Contaminant Detection}

The HFNI valvometer can be used to detect acute pollution in case of accidental contamination, but it has a specific added-value for the detection of chronic pollutions and "silent" and/or transitory pollutions which are difficult or impossible to detect otherwise, due to its $24 / 7$ monitoring capabilities over very long periods of times, the very high sensitivity of bivalve molluscs and a policy of data stocking. Cumulative effects of toxicity can also be assessed based on changes in expected behavior. A transient effect to a single dose exposure can have dramatic impact. HFNI can be a remote witness of 
these events. Interestingly, the bivalve behavior before death is very typical. Identifying the last moments during which it behaved normal and rhythmic can tell when the animal started to become disturbed. If a whole group starts to be disturbed in a similar timeframe, one can speculate that a common driver exists. Such a driver could be a drastic, or subtle but deadly, change in water quality. Preventing and reducing anthropogenic inputs to the marine environment is one of the main objectives of the Marine Directive and the aim of Descriptor 8 is to ensure that levels of contaminants in the marine environment do not give rise to pollution effects (European Commission, 2010) (http://ec.europa.eu/environment/marine/good-environmentalstatus/descriptor-8/index_en.htm). The HFNI potential as a biosensor for heavy metal detection even at low concentration levels has been extensively demonstrated in the laboratory as discussed in several of the papers reviewed here (e.g., Tran et al., 2003).

\section{Petroleum Installations}

Produced water (the water which is produced as a byproduct of oil and gas extraction) is notoriously difficult to monitor, primarily due to its rapid dilution in water currents. Deploying the HFNI system at appropriate locations around oil and gas production units will allow the continuous detection of water quality at biologically-relevant levels. This would cover both intentional discharges but would also give early-warning of unplanned leakages to the water column. A parallel system set up at the sea floor would also have an application to detection of unintentional discharges at the sea floor, for example from pipelines or sub-sea production templates. In this regard, the HFNI valvometer has potential as a monitoring tool for the MSFD-related indicators 8.2.1. "Levels of pollution effects on the ecosystem components concerned, having regard to the selected biological processes and taxonomic groups where a cause/effect relationship has been established" and "8.2.2. Occurrence, origin, extent of significant acute pollution events and their impact on biota physically affected by this pollution" (European Commission, 2010).

\section{Toxic Algae Alerts}

In areas where toxic algae may present a risk to human or culture organism health, remote biosensors could function as an early warning system through the documented changes in the gaping behavior, in reaction to toxic alga, to alert when conventional water sampling is needed. This has been demonstrated in the laboratory as mentioned above, by studying behavior of oysters exposed experimentally to a mimic bloom of harmful algae (e.g., Tran et al., 2010). This would help to reduce the total costs of algal bloom monitoring schemes as conventional sampling (e.g., sample collection by a person, laboratory analysis, etc.) will be required only in the case of a bloom event; or supplement with data from areas where routine sampling is not carried out. This application is relevant to monitor the MSFD indicator 5.2.4 "Species shift in floristic composition such as diatom to flagellate ratio, benthic to pelagic shifts, as well as bloom events of nuisance/toxic algal blooms (e.g., cyanobacteria) caused by human activities" (European Commission, 2010) (see also under aquaculture and bathing beaches).

\section{CONCLUSIONS}

The HFNI valvometry has been effective in recording valve activity behavior of bivalves across several locations, from the tropics to the high Arctic. Its deployment has been performed in harsh weather and sea conditions, and/or in daylight or darkness down to $-30^{\circ} \mathrm{C}$. Studies have been performed to understand biological rhythms, various life history traits and effects of natural and anthropogenic stressors upon bivalve behavior in their natural environment or under laboratory conditions. Relationships between pressures from human activities and climatic influences and their effects on bivalve species have been established using the HFNI valvomenter during the last 15 years. In this regard, this innovative tool holds promise for marine monitoring, allowing managers to assess environmental status of marine and freshwater ecosystems remotely and in near-real time. In the MSFD context, the HFNI valvometer has direct applications for monitoring several Indicators of the MSFD Descriptors "D5. Eutrophication," "D8. Contaminants" and "D11. Energy and Noise"; and indirectly the Descriptors "D4. Food webs" and "D6. Seafloor Integrity" (European Commission, 2010). While bivalve growth rates can provide an indirect measurement of production of key species or trophic groups, bivalve behavior provides an indicator of stress that can be related to worsening water quality conditions in benthic environments as well as in the water column. For this purpose, it is necessary to first, establish the baseline normal gaping behavior of the species been studied. Then, behavioral responses to stressors must be characterized. Comparisons can then be made between stressed and unstressed organisms and infer upon the causes of such stress. Abnormal gaping behavior can reveal episodic incidences of disturbance but there will be times when it is not possible to pinpoint directly the exact cause of that disturbance. When this occurs, the technology reveals the problem becoming the starting point of an enquiry for which complementary sampling in the field and analyses are required. How are we able to distinguish the causes of change in gap behavior? By building a repertoire of behavior and analysing in parallel all available environmental data (local ephemerids, tide table, water temperature, noise). In this view the knowledge obtained by multi-parameter probes is evidently quite helpful: chlorophyll $a$, turbidity, oxygen, etc. Further research should focus on evaluating the HFNI technology performance directly in the field, as a biosensor for different anthropogenic stressors such as increased sedimentation, mining, oil production etc.

\section{AUTHOR CONTRIBUTIONS}

HA: Main writer, literature review, data analysis and interpretation, article concept; JM, Project proponent, technology development, data analysis, interpretation, writer; Data analysis and interpretation, writer, figures; SC: Writer, 
data analysis and interpretation, article concept; DT: Data analysis and interpretation, technology development, writer; PC: Data analysis, technology development; MS: Data analysis and interpretation, technology development; LC: Critical revisions of the document.

\section{ACKNOWLEDGMENTS}

This paper is part of an ongoing collaboration between Akvaplan-niva AS and the UMR CNRS 5805 EPOC (University of Bordeaux and CNRS) aiming to develop the HFNI technology as a reliable biosensor in arctic conditions. This manuscript is a result of DEVOTES (DEVelopment Of innovative Tools for understanding marine biodiversity and

\section{REFERENCES}

Berge, J., Daase, M., Renaud, P. E., Ambrose, W. G. Jr., Darnis, G., Last, K. S., et al. (2015). Unexpected levels of biological activity during the polar night offer new perspectives on a warming arctic. Curr. Biol. 25, 2555-2561. doi: 10.1016/j.cub.2015.08.024

Berge, J., Johnsen, G., Nilsen, F., Gulliksen, B., and Slagstad, D. (2005). Ocean temperature oscillations enable reappearance of blue mussels Mytilus edulis in Svalbard after a 1000 year absence. Mar. Ecol. Prog. Ser. 303, 167-175. doi: 10.3354/meps303167

Bernard, I., Massabuau, J. C., Ciret, P., Sow, M., Sottolichio, A., Pouvreau, S., et al. (2016). In situ spawning in a marine broadcast spawner, the Pacific oyster Crassostrea gigas: timing and environmental triggers. Limnol. Oceanogr. 61, 635-647. doi: 10.1002/lno.10240

Borcherding, J. (2006). Ten years of practical experience with the dreissenamonitor, a biological early warning system for continuous water quality monitoring. Hydrobiologia 556, 417-426. doi: 10.1007/s10750-005-1203-4

Borja, A., Elliott, M., Andersen, J. H., Cardoso, A. C., Carstensen, J., Ferreira, J. G., et al. (2013). Good Environmental Status of marine ecosystems: what is it and how do we know when we have attained it? Mar. Pollut. Bull. 76, 16-27. doi: 10.1016/j.marpolbul.2013.08.042

Bricelj, V. M., and Shumway, S. E. (1998). Paralytic shellfish toxins in bivalve molluscs: occurrence, transfer kinetics, and biotransformation. Rev. Fish. Sci. 6, 315-383. doi: 10.1080/10641269891314294

Chambon, C., Legeay, A., Durrieu, G., Gonzalez, P., Ciret, P., and Massabuau, J.-C. (2007). Influence of the parasite worm Polydora sp. on the behavior of the oyster Crassostrea gigas: a study of the respiratory impact and associated oxidative stress. Mar. Biol. 152, 329-338. doi: 10.1007/s00227-007-0693-1

Chen, W.-Y., Liao, C.-M., Jou, L.-J., and Jau, S.-F. (2010). Predicting bioavailability and bioaccumulation of arsenic by freshwater clam Corbicula fluminea using valve daily activity. Environ. Monit. Assess. 169, 647-659. doi: 10.1007/s10661009-1204-2

European Commission (2008). Directive 2008/56/EC of the European parliament and of the council establishing a framework for community action in the field of marine environmental policy (Marine Strategy Framework Directive). Off. J. Eur. Union L164, 19-40. Available online at: http://eur-lex.europa.eu/legalcontent/en/ALL/?uri=CELEX:32008L0056\&qid=1474884626888

European Commission (2010). Commission decision of 1 september 2010 on criteria and methodological standards on good environmental status of marine waters (notified under document C(2010)5956)(2010/477/EU). Off. J. Eur. Union L232, 12-24. Available online at: http://eur-lex.europa.eu/legal-content/ EN/TXT/?qid=1474884308215\&uri=CELEX:32010D0477(01)

European Commission (2016). Guidelines on the application of the Water Framework Directive (WFD) and the Marine Strategy Framework Directive (MSFD) in Relation to Aquaculture (SWD2016)178). Commission Staff Working Document. Available online at: http://ec.europa.eu/environment/ marine/pdf/SWD_2016_178.pdf

Fournier, E., Tran, D., Denison, F., Massabuau, J.-C., and Garnier-Laplace, J. (2004). Valve closure response to uranium exposure for a freshwater bivalve assessing good Environmental Status) project, funded by the European Union under the 7th Framework Programme, "The Ocean of Tomorrow" Theme (grant agreement no. 308392), www.devotes-project.eu. Financial support has also been received through the CNRS, the University of Bordeaux, the Région Aquitaine, the Norwegian Regional Research Fund in the North (Project number 208974), The French National Research Agency (ANR-15-CE04-0002-02), The Fram Centre Flagship "Effects of climate change on sea and coastal ecology in the north," the Svalbard Environmental Protection Fund (Project 15/133) and by the Russian Foundation for Basic Research and the Research Council of Norway (Project 233635/H30 "Environmental management of petroleum activities in the Barents Sea: Norwegian-Russian collaboration."

(Corbicula fluminea): quantification of the influence of pH. Environ. Toxicol. Chem. 23, 1108-1114. doi: 10.1897/02-604

García-March, J. R., Sanchís Solsona, M. Á., and García-Carrascosa, A. M. (2008). Shell gaping behaviour of Pinna nobilis L., 1758: circadian and circalunar rhythms revealed by in situ monitoring. Mar. Biol. 153, 689-698. doi: 10.1007/s00227-007-0842-6

Haberkorn, H., Tran, D., Massabuau, J.-C., Ciret, P., Savar, V., and Soudant, P. (2011). Relationship between valve activity, microalgae concentration in the water and toxin accumulation in the digestive gland of the Pacific oyster Crassostrea gigas exposed to Alexandrium minutum. Mar. Pollut. Bull. 62, 1191-1197. doi: 10.1016/j.marpolbul.2011.03.034

Jónasson, J. P., Thórarinsdóttir, G. G., Eiríksson, H., and Marteinsdóttir, G. (2004). Temperature tolerance of Iceland scallop, Chlamys islandica (O. F. Müller) under controlled experimental conditions. Aquac. Res. 35, 1405-1414. doi: 10.1111/j.1365-2109.2004.01159.x

Kramer, K. J. M. (2009). "Continuous monitoring of waters by biological early warning systems," in Rapid Chemical and Biological Techniques for Water Monitoring, eds C. Gonzalez, R. Greenwood, and Ph. Quevauviller (Chichester: Wiley), 197-219.

Kramer, K. J. M., Jenner, H. A., and De Zwart, D. (1989). The valve movement response of mussels: a tool in biological monitoring. Hydrobiologia 188/189, 433-443. doi: 10.1007/BF00027811

Mat, A. M., Haberkorn, H., Bourdineaud, J.-P., Massabuau, J.-C., and Tran, D. (2013). Genetic and genotoxic impacts in the oyster Crassostrea gigas exposed to the harmful alga Alexandrium minutum. Aquat. Toxicol. 140-141, 458-465. doi: 10.1016/j.aquatox.2013.07.008

Mat, A. M., Massabuau, J.-C., Ciret, P., and Tran, D. (2012). Evidence for a plastic dual circadian rhythm in the oyster Crassostrea gigas. Chronobiol. Int. 29, 857-867. doi: 10.3109/07420528.2012.699126

Oberhauser, B. (2009). Les huitres bio-vigiles. ARTE. Science TV program X:enius. Journalist: Bettina Oberhauser. 15 July 2009.

Schwartzmann, C., Durrieu, G., Sow, M., Ciret, P., Lazareth, C. E., and Massabuau, J.-C. (2011). In situ giant clam growth rate behavior in relation to temperature: a one-year coupled study of high-frequency noninvasive valvometry and sclerochronology. Limnol. Oceanogr. 56, 1940-1951. doi: 10.4319/lo.2011.56.5.1940

Sow, M., Durrieu, G., Briollais, L., Ciret, P., and Massabuau, J.-C. (2011). Water quality assessment by means of HFNI valvometry and high-frequency data modeling. Environ. Monit. Assess. 182, 155-170. doi: 10.1007/s10661-0101866-9

Tran, D., Ciret, P., Ciutat, A., Durrieu, G., and Massabuau, J.-C. (2003). Estimation of potential and limits of bivalve closure response to detect contaminants: application to cadmium. Environmental Toxicology and Chemistry 22, 914-920. doi: $10.1002 /$ etc. 5620220432

Tran, D., Ciutat, A., Mat, A., Massabuau, J.-C., Hégaret, H., Lambert, C., et al. (2015). The toxic dinoflagellate Alexandrium minutum disrupts daily rhythmic activities at gene transcription, physiological and behavior al levels in the oyster Crassostrea gigas. Aquat. Toxicol. 158, 41-49. doi: 10.1016/j.aquatox.2014.10.023 
Tran, D., Fournier, E., Durrieu, G., and Massabuau, J.-C. (2004). Copper detection in the Asiatic clam Corbicula fluminea: optimum valve closure response. Aquat. Toxicol. 66, 333-343. doi: 10.1016/j.aquatox.2004.01.006

Tran, D., Fournier, E., Durrieu, G., and Massabuau, J.-C. (2007). Inorganic mercury detection by valve closure response in the freshwater clam Corbicula fluminea: Integration of time and water metal concentration changes. Environ. Toxicol. Chem. 26, 1545-1551. doi: 10.1897/06-390R1.1

Tran, D., Haberkorn, H., Soudant, P., Ciret, P., and Massabuau, J.-C. (2010). Behavior al responses of Crassostrea gigas exposed to the harmful algae Alexandrium minutum. Aquaculture 298, 338-345. doi: 10.1016/j.aquaculture.2009.10.030

Tran, D., Nadau, A., Durrieu, G., Ciret, P., Parisot, J.-P., and Massabuau, J.-C. (2011). Field chronobiology of a molluscan bivalve: how the moon and sun cycles interact to drive oyster activity rhythms. Chronobiol. Int. 28, 307-317. doi: 10.3109/07420528.2011.565897
Tran, D., Sow, M., Camus, L., Ciret, P., Berge, J., and Massabuau, J.-C. (2016) In the darkness of the polar night, scallops keep on a steady rhythm. Sci. Rep. 6:32435. doi: 10.1038/srep32435

Conflict of Interest Statement: The authors declare that the research was conducted in the absence of any commercial or financial relationships that could be construed as a potential conflict of interest.

Copyright (C) 2016 Andrade, Massabuau, Cochrane, Ciret, Tran, Sow and Camus. This is an open-access article distributed under the terms of the Creative Commons Attribution License (CC BY). The use, distribution or reproduction in other forums is permitted, provided the original author(s) or licensor are credited and that the original publication in this journal is cited, in accordance with accepted academic practice. No use, distribution or reproduction is permitted which does not comply with these terms. 